\title{
A Comparison between the Spatial Intelligence of the Freshman Engineering Students of Sharif University of Technology and Debrecen University
}

\author{
Rita Nagy-Kondor ${ }^{1 *}$, Saeed Esmailnia² \\ 1 Department of Basic Studies, Faculty of Engineering, University of Debrecen, H-4028 Debrecen, Ótemető u. 2-4, Hungary \\ 2 Psychology Department, University of Science and Research, Islamic Azad University, IR-1477893855 Tehran, P. O. B. 14515/775, \\ Iran \\ * Corresponding author, e-mail: rita@eng.unideb.hu
}

Received: 12 February 2020, Accepted: 10 August 2020, Published online: 23 July 2021

\begin{abstract}
The goal of this paper is to compare freshman engineering students' spatial abilities (Spatial Intelligence) at two universities: Sharif University in Tehran and Debrecen University of Hungary, focusing on both their final mathematical exam performance and their gender so as to ascertain whether the students differ significantly in terms of their spatial abilities and/or their problem solving methods. The tests used to measure spatial intelligence performance and mental rotation was the Purdue Spatial Visualization Test (PSVT Branoff). The test results have been statistically evaluated and conclusions formulated. The results show that there was no significant difference between Iranian and Hungarian freshman engineering students in the performance of mental rotation tasks. However, a general gender difference in spatial ability performance was evident among the Hungarian students but not among the Iranians. The results also shed light on spatial rotation problem-solving methods that appear to be largely specific to females.
\end{abstract}

\section{Keywords}

comparative analysis, problem solving, spatial intelligence, spatial rotation

\section{Introduction}

In recent decades, educators and researchers have developed various test formats to evaluate students' spatial visualisation skills. Spatial ability is very important for mathematics, economic forecasting, geography, engineering and architecture students; it is crucial for their career, therefore engineering and technology educators have investigated students' spatial visualisation abilities and technical graphics skills. Psychologists have also intensively studied spatial visualisation from the perspective of cognition and perception and have said this ability is not determined genetically, but rather it is determined as a result of a long learning process. According to Baranová and Katreničová (2018), spatial ability is the result of lifelong learning and training processes and may change over time. Findings confirm that students' spatial skills can be improved with the help of a geometry course and showed that learning geometry has a significant positive effect on students' spatial skills (Williams et al., 2008).

Spatial abilities are one of the most studied factors of human cognitive function (Carroll, 1993). Recently, however, interest in special abilities has been revitalised, because there is growing evidence of a significant correlation between spatial abilities and educational performance (Lubinski, 2010; Wai et al., 2009). Spatial ability contributes to performance in science, technology, engineering, and mathematics (STEM) domains even the abilities of verbal and mathematical control (Shea et al., 2001; Wai et al., 2009). Individuals with high mathematical ability, spatial ability, and scientific interests are likely to pursue STEM careers (Austin and Hanisch, 1990; Gottfredson, 2003; Wai et al., 2009). Spatial ability is very important for engineering students. Numerous studies have shown that spatial ability has a positive correlation with problem solving ability as well as success at mathematics (Fennema and Sherman, 1977). According to previous studies, spatial abilities are predictors of success in technical education and have a high importance in engineering education (Ault and John, 2010; Nagy-Kondor and Sörös, 2012; Nagy-Kondor, 2010; Nagy-Kondor, 2017).

It can be said that spatial ability not only helps performance in the fields of science, technology, engineering and 
mathematics, but it also controls verbal and mathematical abilities (Dehaene et al., 1999; Shea et al, 2001; Wai et al., 2009; Young et al., 2018). There is also a correlation between the spatial intelligence of preschoolers (Gunderson et al., 2012) and the spatial intelligence of adults (Sella et al., 2016).

There is no consensus definition of spatial ability among scientific associations but it can be said that spatial ability is the ability to manipulate an object or pattern by imagination (Kahle, 1983). Spatial ability is the subjective manipulation of spatial information to determine how a given spatial configuration can be shown if a part of it is rotated, folded, repositioned or transformed (Salthouse et al., 1990). Spatial ability represents skill at solving a visually assigned problem in one's mind (Baranová and Katreničová, 2018). Spatial ability can be defined as the "intrinsic ability" to visualise spatial objects and their developments in one's imagination (Górska and Juščákova, 2003). Gardner (1983) differentiates between seven different types of intelligence: linguistic, logical-mathematical, spatial, musical, physical-kinesthetic, interpersonal and intrapersonal. According to Gardner (1983:p.9) the "spatial intelligence is the ability of forming a mental model of the spatial world and manoeuvring and working with this model".

Interestingly, in some studies, reported differences in spatial abilities between men and women were in favour of men (Voyer et al., 1995). Studies reported that men were significantly better at different mental rotation tests than women (Jansen et al., 2016). Using different approaches (Hirnstein et al., 2009) and self-esteem in judging (Estes and Felker, 2012) potentially affects sex differences. Contrary to social role theory's prediction that sex differences are higher in non-egalitarian societies, scholars have also hypothesised that people in societies with a higher polarity of gender roles would have greater gender differences than people in a more equitable society (Jansen et al., 2016). Sex differences in MRT mental rotation test have been shown to be greater in equality-seeking countries (Lippa et al., 2010). The weaker performance of non-Western cultures is also consistent with the study of Jansen et al. (2019) who showed that the performance of some Asian countries such as Thailand and the Philippines was lower than that of participants with Western cultures. There are few studies examining cultural differences in the performance of mental rotation testing (Jansen et al., 2016). Omani students show poorer MRT performance than German students, and children in Cameroon have lower score than German children (Jansen et al., 2019). Sharps et al. (1993) believe that socio-cultural expectations of being feminine or masculine spatial assignments have a different effect on "boys and girls" mental rotation ability (Saucier et al., 2002).

According to Quaiser-Pohl and Lehmann (2002), women are less likely to have high spatial ability, because they have less spatial experiences than men. According to Nash's (1979) hypothesis in the context of gender-related assignments and Horner (1972) theory, individuals perform better when their self-concept is consistent with their gender-related assignments, and since special abilities are required for masculine tasks, men get higher scores than women. Moreover, there is strong evidence that sex roles have an influence on both the choice of field of study and the performance of individuals in the special tests (Quaiser-Pohl and Lehmann, 2002). Females also tend to underestimate their spatial ability, which is inconsistent with their actual performance in mental rotational tasks. Thus, females' performance in the Mental Rotational Test (MRT) in addition to reflecting their spatial experience is also influenced by their attitudes toward spatial skills (Quaiser-Pohl et al., 2004).

Biological factors have also been discussed as possible causes of this discrepancy. Biological discoveries of factors involved in mental rotation include studies of cerebral involvement. Magnetic Resonance Imaging (MRI) studies often reveal the mental rotation related to activation of the parietal regions (Parsons et al., 2004). Brain structure and the asymmetric quality of the brain can contribute to the spatial ability of the brain. Moreover, since mental rotation (which is a major spatial ability) is controlled by the right hemisphere, research into brain specialisation has shown that men employ mainly the right hemisphere to solve such tasks, whereas women use both hemispheres and especially the left hemisphere to solve these tasks.

In fact, it is argued that women's poor performance in a spatial assignment may be due to the fact that they use verbal strategies to solve and encode spatial assignment. Men's brain is larger than women's and this is a property that has existed since their birth. Most of all these differences in the brain of men and women can be explained by differences in body size (Parsons et al., 2004). However, some researchers believe that even with such an explanation (namely, that sex differences contribute to the brain size), there is also a gender difference that accounts for a difference in the brain sizes of men and women (Caplan et al., 1997).

Geshwind and Galaburda have proposed a complex theory that explains the specialization of the brain hemispheres (Brannon, 2017). This theory is based on inherited 
events, especially the presence of hormones we inherited at birth. In the sensitive embryonic period, Testosterone is an important factor in controlling the growth of the cerebral hemispheres, and Androgen and Oestrogen hormones affect the brain as well as the growth of the inner and outer organs of male and female. These effects may also be related to sex differences in the brain. According to this theory, embryonic hormones make lasting differences in the organization of the cerebral hemispheres and subsequently in the mental abilities.

Injection of the male hormone Testosterone, even once, increases the ability of the male to rotate mental tasks (Parsons et al., 2004). Thus, in homework requiring mental rotation, men are better than women in spatial navigation, mapping knowledge and geography. But in terms of spatial memory, when maps are reviewed to remember the signs on the route, women are better than men (Kimura, 1999). According to Maccoby and Jacklin's hormonal theory, sex differences in cognitive functioning in early adolescence are not seen in adolescence, and Silverman and his co-workers stated that this difference in adolescents is often observed in different cultures as evidence of the influence of a biological factor on the ability to rotate mentally (Parsons et al., 2004).

According to Kass et al. (1998), men are expected to be more successful in new spatial assignments than women because they have more spatial experiences in life according to sexual schema and social learning theory. However, training with feedback improves women's performance in space assignments more than men. This type of exercise not only improves the performance of girls at mental rotation, but the effect also persists even 3 weeks after training. Research evidence suggests that as regards the spatial ability scale, there is a discernible difference between different educational, cultural, and gender groups. Accordingly, in this study, we attempt to study and compare the differences in the spatial ability and problem solving methods of freshman engineering students at two universities, Sharif University of Technology in Tehran and Debrecen University, taking into account the students' gender, educational level, age, and mathematical test scores. We chose to examine students' spatial ability in particular because the results can inform the choice of appropriate teaching tools for the subjects.

\section{Research questions and hypotheses}

The goal of the authors of this manuscript was to see whether there are any correlations in PSVT-R between the two universities in relation to the spatial intelligence of male and female freshman engineering students. During the research, the authors set up three RQs and Hs. The RQs are the following:

- RQ1: Is there a significant relationship between engineering students' gender, age, grade in mathematics and their PSVT-R results?

- RQ2: Is there a significant relationship between engineering students' gender, age, grade and how the PSVT-R problems were solved?

- RQ3: Is there a significant difference between freshman engineering students at the University of Sharif University of Technology in Tehran and the University of Debrecen in terms of PSVT-Rotation performance?

The following are the Hs:

- H1: There is significant relationship between engineering students' gender, age, grade of mathematics and their PSVT-R results - according to previous articles.

- H2: There is no significant relationship between engineering students' gender, age, grade and how the PSVT-R problems were solved.

- H3: There is no significant difference between freshman engineering students at the University of Sharif University of Technology in Tehran and the University of Debrecen in PSVT-Rotation.

\section{Participants}

Participants in this study were 93 freshman engineering students, ranging from 19 to 24 years (mean age $=20.50$, SD age $=1.44), 53$ freshman students were Hungarian engineering students (17 female $32.1 \%$, 36 males $67.9 \%$, mean age $=69.19$, SD age $=0.63)$ and 40 Iranian freshman students were engineering students (10 females $25 \%$, 30 males $75 \%$, mean age $=21 / 75$, DS age $=1 / 51)$. Demographic information about participants' gender, age, nationality, grade of mathematics and how to solve the questions was recorded by the use of a self-assessment questionnaire.

\section{Instrument}

The instrument used in this study is Purdue Spatial Visualization Test (PSVT Branoff). Purdue Spatial Visualization Test (PSVT Branoff) was used to evaluate the construct spatial ability (Branoff and Connolly, 1999). Guay developed the PSVT in 1976 in order to determine student's ability to visualise and recognise orthographic drawings. The PSVT includes three sections: developments, object rotations and views. The PSVT contains 30 questions 
whose difficulty level gradually increase. This test is suitable for those of 13 years of age and more (Guay, 1977). All of the 3D objects in the PSVT have simple geometric shapes. The rotations are the combinations of $90^{\circ}$ and $180^{\circ}$ about the axes. The rotations of the sections show an object in two different positions. The first object is rotated on the $\mathrm{X}, \mathrm{Y}$ or Z-axis, to show the rotation pattern. A second object is presented with five alternative views; one represents the second object subjected to the same rotation as the example depicts. Guay (1980) reports internal consistency coefficient results (KR-20) of 0.87, 0.89, and 0.92 from studies conducted on 217 university students, 51 skilled machinists, and 101 university students respectively.

This is a descriptive-analytic study. After gathering the data through questionnaires, SPSS software (version 25) and descriptive statistics (frequency distribution tables, central index, variability index and standard deviation) and inferential statistics (T-test, Pearson correlation and ANOVA) were used in order to analyse the data. Confidence coefficient of $95 \%$ and significance level of 0.05 were considered in PSVT test.

\section{Results}

In this section the statistical analysis - comprising both descriptive and inferential analyses - is presented to see whether the three null hypotheses are confirmed or rejected. The tables and diagrams are arranged based on the order of the null hypotheses presented in the previous section. Therefore, the tables and diagrams start to highlight the gender, age and maths score respectively.

The data analysis in Table 1 showed that there was a significant correlation between gender and spatial intelligence scores of first-year students among Hungarian
Table 1 Relationship between Spatial Intelligence score and gender

\begin{tabular}{|c|c|c|c|c|}
\hline \multicolumn{3}{|c|}{ Nationality } & Gender & $\begin{array}{c}\text { Spatial } \\
\text { Intelligence } \\
\text { Scores }\end{array}$ \\
\hline \multirow{6}{*}{ Hungary } & \multirow{3}{*}{ Gender } & $\begin{array}{l}\text { Pearson } \\
\text { Correlation }\end{array}$ & 1 & $-0.284^{*}$ \\
\hline & & Sig. (2-tailed) & & 0.039 \\
\hline & & $\mathrm{N}$ & 53 & 53 \\
\hline & \multirow{3}{*}{$\begin{array}{l}\text { Spatial } \\
\text { Intelligence } \\
\text { Scores }\end{array}$} & $\begin{array}{l}\text { Pearson } \\
\text { Correlation }\end{array}$ & $-0.284^{*}$ & 1 \\
\hline & & Sig. (2-tailed) & 0.039 & \\
\hline & & $\mathrm{N}$ & 53 & 53 \\
\hline \multirow{6}{*}{ Iranian } & \multirow{3}{*}{ Gender } & $\begin{array}{l}\text { Pearson } \\
\text { Correlation }\end{array}$ & 1 & -0.025 \\
\hline & & Sig. (2-tailed) & & 0.880 \\
\hline & & $\mathrm{N}$ & 40 & 40 \\
\hline & \multirow{3}{*}{$\begin{array}{l}\text { Spatial } \\
\text { Intelligence } \\
\text { Scores }\end{array}$} & $\begin{array}{l}\text { Pearson } \\
\text { Correlation }\end{array}$ & -0.025 & 1 \\
\hline & & Sig. (2-tailed) & 0.880 & \\
\hline & & $\mathrm{N}$ & 40 & 40 \\
\hline
\end{tabular}

* Correlation is significant at the 0.05 level (2-tailed).

engineering students ( $p=0.039, r=-0.2488)$. Evidence indicates a significant correlation $(p<0.05)$ between gender and spatial intelligence score for these students, but among Iranian students $(p=0.88, r=-0.025)$ there isn't a significant correlation $(p>0.05)$ between the gender of individuals and their spatial intelligence scores.

In Fig. 1 two groups of answers given by Hungarian and Iranian female students are compared. As can be observed, the most significant discrepancies are the answers given to questions number 13 (90\% Iranian and $53 \%$ Hungarian with difference of $37 \%$ ), number 17 (100\% Iranian and $59 \%$ Hungarian with the difference of $41 \%$ ), and question $29(100 \%$ Iranian and $59 \%$ Hungarian with the difference

PSVT-R

Female

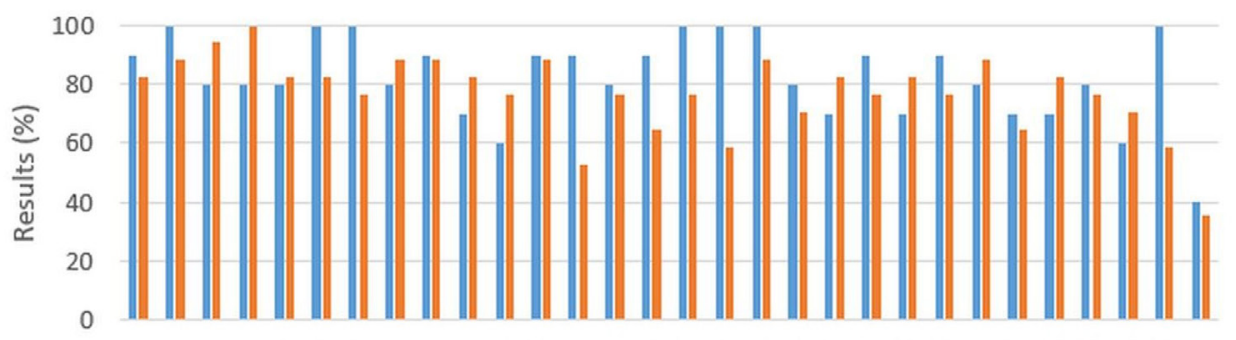

1. 2. 3. 4. 5. 6. 7. 8. 9. $10.11 .12 .13 .14 .15 .16 .17 .18 .19 \cdot 20.21 .22 .23 .24 .25 \cdot 26.27 .28 .29 .30$.

Tasks

- Iran $\quad$ Hungary

Fig. 1 Results of Hungarian and Iranian female students 
of $41 \%$ ). The lowest scores obtained were for question number 11 (60\% Iranian), question 13 (53\% Hungarian), question 17 (59\% Hungarian), question 28 (60\% Iranian), question 29 (59\% Hungarian) and question 30 (40\% Iranian and $35 \%$ Hungarian). The highest scores obtained were for question number 2 (100\% Iranian) question 3 (94\% Hungarian) question 4 (100\% Hungarian) and for questions $6,7,16,17,18$, and 29 (100\% Iranian).

However, it can be observed that in Fig. 2 Hungarian and Iranian male students are compared. As you can see the most difference answers in PSVT-R in male groups are related to number 29 (93\% Iranian and $61 \%$ Hungarian with difference of $32 \%$ ), number 30 (27\% Iranian and $44 \%$ Hungarian with difference of $18 \%$ ). The least score gained was question number 13 (72\% Hungarian), number 22 (73\% Iranian), number 28 (77\% Iranian), number 29 (61\% Hungarian), number 30 (27\% Iranian and $44 \%$ Hungarian). The highest scores obtained are for question number 1, 2, 7, 8 and 20 (97\% Hungarian), number 9, 14, 15 and 29 (93\% Iranian).

The results in Table 2 also indicates that there wasn't a significant relationship between the spatial intelligence scores of freshman engineering students and their age in both Hungarian $(r=-0.038, p=0.785)$ and Iranian $(r=0.059, p=0.717)$.

Regarding the correlation between math scores and spatial intelligence scores, the results in Table 3 revealed that there was a significant $(p<0.05)$ correlation between math scores and spatial intelligence scores $(r=0.277, p=0.045)$ in Hungarian engineering students. But there was no significant correlation $(p>0.05)$ between mathematics scores and spatial intelligence $(r=-0.095, p=0.559)$ among Iranian freshmen students.
We have observed three spatial rotation problem-solving methods:

- A1. Only the shape was rotated in their mind.

- A2. The shape and the axes were also rotated in their mind.

- A3. Only axes were rotated in their mind.

As can be observed in Table 4, a significant percentage of engineering freshman students used the form rotation method to solve questions (54\% of Hungarian students and $52 \%$ of Iranian students) and the least frequent solution is turning the axis in the mind (10.9\% among Hungarian students and $12 \%$ are Iranian).

Among Iranian students (20\%) of females just rotated shapes in their mind to find the right answer but in Hungarian students (29\%) rotated shapes in their mind to find the right answer. Likewise, (37\%) of Iranian male students solved the problems using only the rotation of the shapes in their mind to solve the problems, but in Hungarian Students (56 \%) using only the rotation of the shapes in their mind to solve the problems. Males prefer to solve the problem with this method. On the other hand, the results suggest that (40\%) of Iranian females rotated both shape and axis to come up with the right answers but in Hungarian students (35\%) rotated both shape and axis to come up with the right answers, while just (17\%) of male Iranian students and (28\%) of Hungarian students solved the PSVT-R problems by rotating both shapes and axis in their mind. Females prefer to solve the problem with this method. $10 \%$ of Iranian females, $24 \%$ of Hungarian females and $7 \%$ of Iranian males and $3 \%$ of Hungarian males used both shape and axis in solving problems in the test. Men less typically use this method.

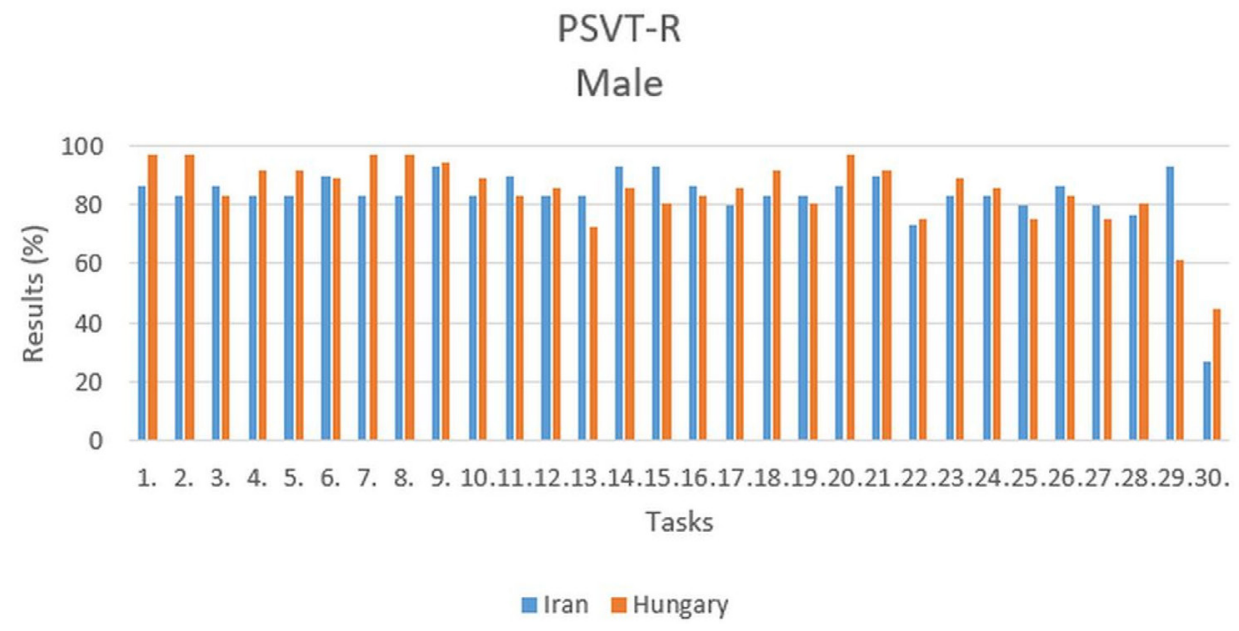

Fig. 2 Results of Hungarian and Iranian male students 
Table 2 Relationship between Spatial Intelligence score and age

\begin{tabular}{|c|c|c|c|c|}
\hline \multicolumn{3}{|c|}{ Nationality } & \multirow{2}{*}{$\begin{array}{c}\text { AGE } \\
-0.038\end{array}$} & \multirow{2}{*}{$\begin{array}{c}\begin{array}{c}\text { Spatial } \\
\text { Intelligence } \\
\text { Scores }\end{array} \\
1\end{array}$} \\
\hline \multirow{6}{*}{ Hungary } & \multirow{3}{*}{$\begin{array}{l}\text { Spatial } \\
\text { Intelligence } \\
\text { Scores }\end{array}$} & $\begin{array}{l}\text { Pearson } \\
\text { Correlation }\end{array}$ & & \\
\hline & & Sig. (2-tailed) & 0.785 & \\
\hline & & $\mathrm{N}$ & 53 & 53 \\
\hline & \multirow{3}{*}{ AGE } & $\begin{array}{l}\text { Pearson } \\
\text { Correlation }\end{array}$ & 1 & -0.038 \\
\hline & & Sig. (2-tailed) & & 0.785 \\
\hline & & $\mathrm{N}$ & 53 & 53 \\
\hline \multirow{6}{*}{ Iranian } & \multirow{3}{*}{$\begin{array}{l}\text { Spatial } \\
\text { Intelligence } \\
\text { Scores }\end{array}$} & $\begin{array}{l}\text { Pearson } \\
\text { Correlation }\end{array}$ & 0.059 & 1 \\
\hline & & Sig. (2-tailed) & 0.717 & \\
\hline & & $\mathrm{N}$ & 40 & 40 \\
\hline & \multirow{3}{*}{ AGE } & $\begin{array}{l}\text { Pearson } \\
\text { Correlation }\end{array}$ & 1 & 0.059 \\
\hline & & Sig. (2-tailed) & & 0.717 \\
\hline & & $\mathrm{N}$ & 40 & 40 \\
\hline
\end{tabular}

Table 3 Relationship between Spatial Intelligence score and Math score

\begin{tabular}{|c|c|c|c|c|c|}
\hline \multicolumn{4}{|c|}{ Nationality } & \multirow{2}{*}{$\begin{array}{l}\text { Math } \\
\text { score } \\
1.000\end{array}$} & \multirow{2}{*}{$\begin{array}{c}\begin{array}{c}\text { Spatial } \\
\text { Intelligence } \\
\text { Scores }\end{array} \\
0.277^{*}\end{array}$} \\
\hline \multirow{12}{*}{ 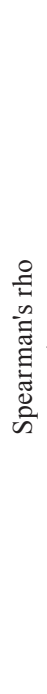 } & \multirow{6}{*}{ Hungary } & \multirow{3}{*}{ Math score } & $\begin{array}{l}\text { Correlation } \\
\text { Coefficient }\end{array}$ & & \\
\hline & & & Sig. (2-tailed) & & 0.045 \\
\hline & & & $\mathrm{N}$ & 53 & 53 \\
\hline & & \multirow{3}{*}{$\begin{array}{l}\text { Spatial } \\
\text { Intelligence } \\
\text { Scores }\end{array}$} & $\begin{array}{l}\text { Correlation } \\
\text { Coefficient }\end{array}$ & $0.277^{*}$ & 1.000 \\
\hline & & & Sig. (2-tailed) & 0.045 & \\
\hline & & & $\mathrm{N}$ & 53 & 53 \\
\hline & \multirow{6}{*}{ Iranian } & \multirow{3}{*}{ Math score } & $\begin{array}{l}\text { Correlation } \\
\text { Coefficient }\end{array}$ & 1.000 & -0.095 \\
\hline & & & Sig. (2-tailed) & & 0.559 \\
\hline & & & $\mathrm{N}$ & 40 & 40 \\
\hline & & \multirow{3}{*}{$\begin{array}{l}\text { Spatial } \\
\text { Intelligence } \\
\text { Scores }\end{array}$} & $\begin{array}{l}\text { Correlation } \\
\text { Coefficient }\end{array}$ & -0.095 & 1.000 \\
\hline & & & Sig. (2-tailed) & 0.559 & \\
\hline & & & $\mathrm{N}$ & 40 & 40 \\
\hline
\end{tabular}

* Correlation is significant at the 0.05 level (2-tailed).

In answer to the question: Whether the drawing of the axes helped to find the solution on PSVT-Rotation? It can be said that $53 \%$ of female, $31 \%$ of male Iranian students, $40 \%$ of female and $20 \%$ of male Iranian students answered yes axes help them. On the other hand, $30 \%$ of female, $40 \%$ of male Iranian students, $35 \%$ of female and $56 \%$ of male Hungarian students answered no axes help them. In general, the mean $45 \%$ of female in both countries answered yes, but $16 \%$ of male students answered yes. From one hand, $21 \%$ of female in both countries answered no, but $31 \%$ of male students answered no.
Table 4 How to solve questions?

\begin{tabular}{|c|c|c|c|c|c|c|}
\hline \multicolumn{3}{|c|}{ Answers (A1., A2. or A3.) } & Freq. & Percent & $\begin{array}{c}\text { Valid } \\
\text { Percent }\end{array}$ & $\begin{array}{c}\text { Cumulat. } \\
\text { Percent }\end{array}$ \\
\hline \multirow{6}{*}{ 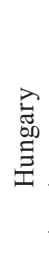 } & \multirow{4}{*}{ Valid } & A1. & 25 & 47.2 & 54.3 & 54.3 \\
\hline & & A2. & 16 & 30.2 & 34.8 & 89.1 \\
\hline & & A3. & 5 & 9.4 & 10.9 & 100.0 \\
\hline & & Total & 46 & 86.8 & 100.0 & \\
\hline & Missing & System & 7 & 13.2 & & \\
\hline & Total & & 53 & 100.0 & & \\
\hline \multirow{6}{*}{$\underset{\Xi}{\Xi}$} & \multirow{4}{*}{ Valid } & A1. & 13 & 32.5 & 52.0 & 52.0 \\
\hline & & A 2 . & 9 & 22.5 & 36.0 & 88.0 \\
\hline & & A3. & 3 & 7.5 & 12.0 & 100.0 \\
\hline & & Total & 25 & 62.5 & 100.0 & \\
\hline & Missing & System & 15 & 37.5 & & \\
\hline & Total & & 40 & 100.0 & & \\
\hline
\end{tabular}

The results showed that there was no significant relationship between the spatial intelligence scores of freshman engineering students and their way of solving questions between Hungarian students and Iranian students. The results also showed that there was a significant difference between female and male in the two countries, it means the axes help female more than male.

Independent $T$-test results indicated that there was no significant difference between nationality (Iranian, Hungarian) and the scores of PSVT-R tests $(T=-0.408$, $d f=88.768, p=0.685)$.

In PSVT-R test, the most significant differences were revealed in the answers given to questions number 13 (85\% Iranian and $66 \%$ Hungarian with difference of $19 \%$ ), number 15 (93\% Iranian and $75 \%$ Hungarian with the difference of $17 \%$ ), and question 29 (95\% Iranian and $60 \%$ Hungarian with the difference of $35 \%$ ). The lowest scores obtained were for question number 13 (66\% Hungarian), question 22 (73\% Iranian), question 28 (73\% Iranian), question 29 (60\% Hungarian), question 30 (30\% Iranian and $42 \%$ Hungarian). The highest scores obtained were for questions number 2, 4 and 8 (94\% Hungarian), questions 6, 9 and 15 (93\% Iranian) and for question 29 (95\% Iranian).

\section{Conclusion and further research}

The spatial abilities and problem-solving methods of Iranian and Hungarians freshman engineering students have been studied in this paper. Their abilities were measured by several tests. All data were collected during the spring semester of 2019. Results of the current study indicated that students' performance in the PSVT test was related to their gender. Male students were stronger than female students. However, this difference was found only 
among the Hungarian students; there wasn't any gender difference observable in the Iranian students' PSVT test scores.

The ability to mentally rotate the shapes has produced one of the largest gender differences in cognitive sciences (Linn and Petersen, 1985). There are a number of explanations for the gender difference in mental rotation. One of the researches provides environmental, social, and cultural explanations of gender differences in mental rotation (Sharps et al., 1993). It has been argued that Western cultures regard spatial work as a masculine nature, and that the difference in spatial ability may be minimised by creating the notion that spatial tasks are appropriate for female participants as well as male participants (Richardson, 1994; Subrahmanyam and Greenfield, 1994).

Németh et al. (2007) attempted to identify possible causes of gender differences in learning. Studies showed that common mistakes in special intelligence can be one of the possible reasons, because in some cases, female students often make more mistakes than men especially in respect of spatial abilities (Jansen-Osmann and Heil, 2007). The present study is consistent with those studies and has shown that the manner of solving PSVT test questions differs between men and women, since $56 \%$ of Hungarian male students just rotate the shape to solve PSVT test questions, but among women the most frequent solution to PSVT test questions is rotating the shape and axis in the mind (35\%). Subjects were also asked if they were helped by the axes in solving the questions.

\section{References}

Ault, H. K., John, S. (2010) "Assessing and Enhancing Visualization Skills of Engineering Students in Africa: A Comprehensive Study", The Engineering Design Graphics Journal, 74(2), pp. 12-20. [online] Available at: http://citeseerx.ist.psu.edu/ viewdoc/download?doi=10.1.1.858.5077\&rep=rep1\&type $=$ pdf [Accessed: 20 January 2020]

Austin, J. T., Hanisch, K. A. (1990) "Occupational attainment as a function of abilities and interests: A longitudinal analysis using project TALENT data", Journal of Applied Psychology, 75(1), pp. 77-86. https://doi.org/10.1037/0021-9010.75.1.77

Baranová, L., Katreničová, I. (2018) "Role of Descriptive geometry course in development of students' spatial visualization skills", Annales Mathematicae et Informaticae, 49, pp. 21-32. https://doi.org/10.33039/ami.2018.04.001

Brannon, L. (2017) "Gender: Psychological Perspectives", Routledge, New York, USA.

https://doi.org/10.4324/9781315621821

Branoff, T. J., Connolly, P. E. (1999) "The Addition of Coordinate Axes to the Purdue Spatial Visualization Test-Visualization of Rotations: A Study at Two Universities", presented at 1999 Annual Conference, Charlotte, NC, USA, pp. 4.506.1-4.506.9. [online] Available at: https://peer.asee.org/7541 [Accessed: 20 January 2020]
There is a significant difference here as well. $56 \%$ of men reported that axes did not help them and $53 \%$ of women reported that axes helped them. Thus, these spatial differences can be observed in both genders. Females prefer to use method 2 for spatial rotation problem-solving: the shape and the axes were also rotated in their mind. Females prefer to use method 1 for spatial rotation problem-solving: only the shape was rotated in their mind. There are some students (rather females) solve the task with method 3, so without rotation of objects, only axes were rotated in their mind. The axes may help females to solve the spatial rotation problem.

Results of the survey prove that imagining a spatial figure causes problems for many students and in this way, it affects solving spatial tasks as well. We have also observed gender differences between male and female in our research regarding their spatial abilities. Since learning has a positive effect on the spatial abilities of both females and males, it would be very useful educators could give training in spatial ability to students in both high schools and universities. If teachers and university professors devote more time to improve a student's spatial ability (special intelligence) at the right age with an appropriate teaching strategy, it will help the student to have a more developed spatial intelligence, regardless of their gender. As many students have problems imagining a spatial object, it is necessary to use as many visual aids as possible for their development of spatial ability (computer programs, animations, paper models, etc.

Caplan, P. J., Crawford, M., Hyde, J. S., Richardson, J. T. E. (1997) "Gender Differences in Human Cognition", Oxford University Press, New York, NY, USA. https://doi.org/10.1093/acprof:oso/9780195112917.001.0001

Carroll, J. B. (1993) "Human Cognitive Abilities: A Survey of FactorAnalytic Studies", Cambridge University, Cambridge, UK. https://doi.org/10.1080/00140139508925174

Dehaene, S., Spelke, E., Pinel, P., Stanescu, R., Tsivkin, S. (1999) "Sources of Mathematical Thinking: Behavioral and BrainImaging Evidence", Science, 284, pp. 970-974. https://doi.org/10.1126/science.284.5416.970

Estes, Z., Felker, S. (2012) "Confidence Mediates the Sex Difference in Mental Rotation Performance", Archives of Sexual Behavior, 41(3), pp. 557-570. https://doi.org/10.1007/s10508-011-9875-5

Fennema, E., Sherman, J. (1977) "Sex-Related Differences in Mathematics Achievement, Spatial Visualization and Affective Factors", American Educational Research Journal, 14(1), pp. 51-71.

https://doi.org/10.3102/00028312014001051

Gardner, H. (1983) "Frames of mind: the theory of multiple intelligences", Basic Books, New York, NY, USA. 
Górska, R. A., Juščákova, Z. (2003) "A Pilot Study of a New Testing Method for Spatial Abilities Evaluation", Journal for Geometry and Graphics, 7(2), pp. 237-246. [online] Available at: http://www.heldermann-verlag.de/jgg/jgg07/j7h2gors.pdf [Accessed: 20 January 2020]

Gottfredson, L. S. (2003) "The Challenge and Promise of Cognitive Career Assessment", Journal of Career Assessment, 11(2), pp. 115-135. https://doi.org/10.1177/1069072703011002001

Guay, R. B. (1977) "Purdue spatial visualization test-visualization of rotations", Purdue Research Foundation, West Lafayette, IN, USA.

Guay, R. B. (1980) "Spatial Ability Measurement: A Critique and an Alternative", presented at American Educational Research Association Annual Meeting, Boston, MA, USA, Apr., 7-11, 1980.

Gunderson, E. A., Ramirez, G., Beilock, S. L., Levine, S. C. (2012) "The relation between spatial skill and early number knowledge: The role of the linear number line", Developmental psychology, 48(5), pp. 1229-1241. https://doi.org/10.1037/a0027433

Hirnstein, M., Bayer, U., Hausmann, M. (2009) "Sex-specific response strategies in mental rotation", Learning and Individual Differences, 19(2), pp. 225-228.

https://doi.org/10.1016/j.lindif.2008.11.006

Horner, M. S. (1972) "The motive to avoid success and changing aspirations of women", In: Bardwick, J. M. (ed.) Readings on the psychology of women, Harper \& Row, New York, NY, USA, pp. 62-67.

Jansen, P., Paes, F., Hoja, S., Machado, S. (2019) "Mental Rotation Test Performance in Brazilian and German Adolescents: The Role of Sex, Processing Speed, and Physical Activity in Two Different Cultures", Frontiers in Psychology, 10, Article number: 945. https://doi.org/10.3389/fpsyg.2019.00945

Jansen, P., Zayed, K., Osmann, R. (2016) "Gender differences in mental rotation in Oman and Germany", Learning and Individual Differences, 51, pp. 284-290.

https://doi.org/10.1016/j.1indif.2016.08.033

Jansen-Osmann, P., Heil, M. (2007) "Suitable stimuli to obtain (no) gender differences in the speed of cognitive processes involved in mental rotation", Brain and Cognition, 64(3), pp. 217-227. https://doi.org/10.1016/j.bandc.2007.03.002

Kahle, J. B. (1983) "The Disadvantaged Majority: Science Education for Women", AETS Outstanding Paper for 1983, Carolina Biological Supply Company, Burlington, NC, USA, ED 242 561. [online] Available at: https://files.eric.ed.gov/fulltext/ED242561.pdf [Accessed: 20 January 2020]

Kass, S. J., Ahlers, R. H., Dugger, M. (1998) "Eliminating Gender Differences Through Practice in an Applied Visual Spatial Task", Human Performance, 11(4), pp. 337-349. https://doi.org/10.1207/s15327043hup1104_3

Kimura, D. (1999) "Sex and cognition", MIT Press, Cambridge, MA, USA.

Linn, M. C., Petersen, A. C. (1985) "Emergence and Characterization of Sex Differences in Spatial Ability: A Meta-Analysis", Child Development, 56(6), pp. 1479-1498.

https://doi.org/10.2307/1130467
Lippa, R. A., Collaer, M. L., Peters, M. (2010) "Sex Differences in Mental Rotation and Line Angle Judgments Are Positively Associated with Gender Equality and Economic Development Across 53 Nations", Archives of Sexual Behavior, 39(4), pp. 990-997. https://doi.org/10.1007/s10508-008-9460-8

Lubinski, D. (2010) "Spatial ability and STEM: A sleeping giant for talent identification and development", Personality and Individual Differences, 49(4), pp. 344-351.

https://doi.org/10.1016/j.paid.2010.03.022

Nagy-Kondor, R., Sörös, C. (2012) "Engineering students' spatial abilities in Budapest and Debrecen", Annales Mathematicae et Informaticae, 40, pp. 187-201. [online] Available at: http://publikacio.uni-eszterhazy.hu/id/eprint/2682 [Accessed: 20 January 2020]

Nagy-Kondor, R. (2010) "Spatial Ability, Descriptive Geometry and Dynamic Geometry Systems", Annales Mathematicae et Informaticae, 37, pp. 199-210. [online] Available at: http://publikacio.uni-eszterhazy.hu/3195/1/AMI_37_ from199to210.pdf [Accessed: 20 January 2020]

Nagy-Kondor, R. (2017) "Spatial Ability: Measurement and Development", In: Khine, M. S. (ed.) Visual-Spatial Ability in STEM Education: Transforming Research into Practice, Springer, Cham, Switzerland, pp. 35-58 https://doi.org/10.1007/978-3-319-44385-0 3

Nash, S. C. (1979) "Sex role as a mediator of intellectual functioning", In: Wittig, M. A., Petersen, A. C. (eds.) Sex-related differences in cognitive functioning: Developmental issues, Academic Press, New York, NY, USA, pp. 263-302.

Németh, B., Sörös, C., Hoffmann, M. (2007) "Typical mistakes in Mental Cutting Test and their consequences in gender differences", Teaching Mathematics and Computer Science, 5(2), pp. 385-392. https://doi.org/10.5485/TMCS.2007.0169

Parsons, T. D., Larson, P., Kratz, K., Thiebaux, M., Bluestein, B., Buckwalter, J. G., Rizzo, A. A. (2004) "Sex differences in mental rotation and spatial rotation in a virtual environment", Neuropsychologia, 42(4), pp. 555-562.

https://doi.org/10.1016/j.neuropsychologia.2003.08.014

Quaiser-Pohl, C., Lehmann, W. (2002) "Girls' spatial abilities: Charting the contributions of experiences and attitudes in different academic groups", British Journal of Educational Psychology, 72(2), pp. $245-260$

https://doi.org/10.1348/000709902158874

Quaiser-Pohl, C., Lehmann, W., Eid, M. (2004) "The relationship between spatial abilities and representations of large-scale space in children - a structural equation modeling analysis", Personality and Individual Differences, 36(1), pp. 95-107. https://doi.org/10.1016/S0191-8869(03)00071-0

Richardson, J. T. E. (1994) "Gender Differences in Mental Rotation", Perceptual and Motor Skills, 78(2), pp. 435-448. https://doi.org/10.2466/pms.1994.78.2.435

Salthouse, T. A., Babcock, R. L., Skovronek, E., Mitchell, D. R. D., Palmon, R. (1990) "Age and experience effects in spatial visualization", Developmental Psychology, 26(1), pp. 128-136. https://doi.org/10.1037/0012-1649.26.1.128 
Saucier, D. M., McCreary, D. R., Saxberg, J. K. J. (2002) "Does gender role socialization mediate sex differences in mental rotations?", Personality and Individual Differences, 32(6), pp. 1101-1111. https://doi.org/10.1016/S0191-8869(01)00106-4

Sella, F., Sader, E., Lolliot, S., Cohen Kadosh, R. (2016) "Basic and advanced numerical performances relate to mathematical expertise but are fully mediated by visuospatial skills", Journal of Experimental Psychology: Learning, Memory, and Cognition, 42(9), pp. 1458-1472.

https://doi.org/10.1037/xlm0000249

Sharps, M. J., Welton, A. L., Price, J. L. (1993) "Gender and Task in the Determination of Spatial Cognitive Performance", Psychology of Women Quarterly, 17(1), pp. 71-83.

https://doi.org/10.1111/j.1471-6402.1993.tb00677.x

Shea, D. L., Lubinski, D., Benbow, C. P. (2001) "Importance of assessing spatial ability in intellectually talented young adolescents: A 20-year longitudinal study", Journal of Educational Psychology, 93(3), pp. 604-614.

https://doi.org/10.1037/0022-0663.93.3.604

Subrahmanyam, K., Greenfield, P. M. (1994) "Effect of video game practice on spatial skills in girls and boys", Journal of Applied Developmental Psychology, 15(1), pp. 13-32. https://doi.org/10.1016/0193-3973(94)90004-3
Voyer, D., Voyer, S., Bryden, M. P. (1995) "Magnitude of sex differences in spatial abilities: A meta-analysis and consideration of critical variables", Psychological Bulletin, 117(2), pp. 250-270. https://doi.org/10.1037/0033-2909.117.2.250

Wai, J., Lubinski, D., Benbow, C. P. (2009) "Spatial ability for STEM domains: Aligning over 50 years of cumulative psychological knowledge solidifies its importance", Journal of Educational Psychology, 101(4), pp. 817-835. https://doi.org/10.1037/a0016127

Williams, A., Sutton, K., Allen, R. (2008) "Spatial Ability: Issues Associated with Engineering and Gender", In: $19^{\text {th }}$ Annual Conference of the Australasian Association for Engineering Education: To Industry and Beyond, Institution of Engineers, Yeppon, Australia, pp. 228-233. [online] Available at: http://citeseerx.ist.psu.edu/viewdoc/ download?doi=10.1.1.505.2140\&rep=rep1\&type=pdf [Accessed: 20 January 2020]

Young, C. J., Levine, S. C., Mix, K. S. (2018) "The Connection Between Spatial and Mathematical Ability Across Development", Frontiers in Psychology, 9, pp. 1-17.

https://doi.org/10.3389/fpsyg.2018.00755 